\title{
A pós-graduação em engenharia no Brasil: uma perspectiva histórica no âmbito das políticas públicas
}

\section{Resumo}

Este artigo apresenta um relato da pósgraduação em engenharia no Brasil a partir de marcos importantes na história do ensino superior brasileiro. $\bigcirc$ trabalho considera a legislação estabelecida em diferentes momentos analisados e o contexto de instituições acadêmicas e científicas na construção da pós-graduação brasileira. São apresentadas, ainda, as principais agências nacionais de fomento para o desenvolvimento da Ciência e Tecnologia, os primeiros anos de pós-graduação em engenharia e o sistema de avaliação.

Palavras-chave: Ensino. Engenharia. Pós-graduação. Avaliação.

\section{Abstract}

Engineering

post-

\section{graduation in}

\section{Brazil: a historical}

\section{perspective}

This paper presents a report on the engineering post-graduation in Brazil based on some important landmarks in the history of the Brazilian higher education. The work takes into account the legislation established in different studied periods of time and the context of the academic and scientific institutions during the development of the Brazilian post-graduate courses. Furthermore, the main national sponsoring agencies for the development of science and

technology, as well as the first years of the engineering postgraduation and the associated evaluation system are introduced and analyzed.

Keywords: Education. Engineering. Postgraduation. Evaluation.

Dr. em Inteligência Artificial Aplicada

à Educação, Universidade de

Huddersfield, Inglaterra Diretor Científico da FAPEMIG Fundação de Amparo à Pesquisa do Estado de Minas Gerais marioneto@fapemig.br
Resúmen La posgraduación en ingeniería en
Brasil: una perspectiva histórica

Este trabajo presenta un relatório de la pos-graduación en ingeniería en Brasil desde marcos importantes de la história de la enseñanza superior brasilera. Se 
considera aquí, la legislación establecida em diferentes momentos analizados y el contexto de las instituciones academicas y científicas que construyeron la posgraduación. También son presentados la participación de las agencias de fomento en el desenvolvimiento de la ciencia y tecnologia, el início de la pos-

graduación en ingeniería y el sistema de evaluación.

Palabras clave: Enseñanza. Ingeniería. Pos-graduación. Evaluación.

\section{Introdução}

A história do ensino superior brasileiro pode ser localizada a partir da Companhia de Jesus, que manteve cursos superiores de artes (filosofia e ciências) e inclusive os de teologia em Collégios (grifo nosso) na Bahia', Rio de Janeiro, OlindaRecife, Belém-São Luís, São Paulo e Mariana (CUNHA, 1989). Até a expulsão dos jesuítas dos territórios portugueses, em 1759, as experiências relativas a ensino superior no Brasil estiveram atreladas às ações dos "soldados de cristo", cujas humanidades visavam a preparar uma elite letrada para as funções burocráticas e bacharelescas na direção do reino português no Brasil. Assim, ao término do curso, havia aqueles que, por exemplo, buscavam a Universidade de Coimbra como caminho para a complementação de sua formação, caso quisessem dedicar-se ao estudo de Direito; ou de Montpellier na França, para fazer seus estudos de Medicina (FÁVERO, 1977).
Além dos colégios humanistas, os jesuítas foram precursores da ciência e da pesquisa, atribuindo-se a eles experimentações científicas, dentre as quais se destaca a instalação de um observatório astronômico em 1730, no Morro do Castelo, no Rio de Janeiro $^{2}$. Posteriormente, a herança jesuítica foi levada adiante por dois astrônomos portugueses que realizaram estudos e observações regulares, a partir de 1780 .

Concomitantemente aos empreendimentos dos jesuítas desenvolviam-se estudos de matemática e cartografia em algumas fortificações militares do Brasil colônia, cujo objetivo era aprimorar as técnicas de defesa com construções cada vez mais estruturadas para esse fim. Nessa perspectiva de defesa e inovação de técnicas de edificações, é possível apontar a gênese das experimentações de engenharia no Brasil, que, após a sua consolidação como demanda militar, passa a ser uma matéria de estudos, especialmente na formação dos oficiais que planejavam as estratégias defensivas, desde a logística arquitetônica até a aplicação da artilharia. Dessa forma, a Carta Régia ${ }^{3}$, de 15 de janeiro de 1699, pretendia iniciar atividades de ensino de engenharia militar no Brasil, estabelecendo as bases para a formação de técnicos na arte de construções e fortificações, através da Aula ${ }^{4}$ de Fortificação.

Durante o século XVIII, várias experiências de ensino militar foram realizadas, funcionando, por exemplo, no Rio de Janeiro e utilizando o sistema de Aulas Régias, estudos pautados

\footnotetext{
${ }^{1}$ Em 1575, foram concedidos os primeiros graus de bacharel aos formados pelo primeiro curso de artes do Colégio da Bahia. Em 1578, foram conferidos os primeiros títulos de mestre em artes e, em 1581, os primeiros graus de doutor (SCHWARTZMAN, 1979, p. 341$)$.

${ }^{2}$ Ver sítio do Observatório Nacional. Dispopnível em: <http://www.on.br>. Acesso em: 20 jul. 2007.

${ }^{3}$ Em Pardal (1985), há uma transcrição desta Carta, bem como o estatuto da Real Academia de Artilharia, Fortificação e Desenho de 1792.

${ }^{4}$ Uma instituição de ensino começava, em geral, com a denominação de Aula, passando, depois, à de Academia (PARDAL, 1985).
} 
em uma bibliografia clássica que tinha como manual, dentre outros instrumentos, o Método Lusitânico de Desenhar as Fortificações das Praças Regulares e Irregulares (PIMENTEL, 1680). A evolução das Aulas levou à criação da Real Academia de Artilharia, Fortificação e Desenho, em 17 de dezembro de 1792. Nela os futuros oficiais da infantaria e artilharia concluíam seus cursos, respectivamente, em três e cinco anos, e os oficiais de engenharia cursavam mais um ano com cadeiras de Arquitetura Civil, Materiais de Construção, Caminhos e Calçadas, Hidráulica, Pontes, Canais, Diques e Comportas (PARDAL, 1985).

A formação técnica recebida constituía um seleto grupo de sujeitos cujos conhecimentos, naquele período, tornava-os aptos a estudos científicos avançados, preparando uma elite militar que daria forma aos primeiros estudos superiores de ciências exatas e as suas aplicações. No entanto, o marco fundamental para o ensino superior foi a vinda da família real portuguesa para o Brasil, em 1808, fato que permitiu a criação de diversas instituições, algumas delas oferecendo cursos de ensino superior, como a Academia Real dos GuardasMarinha $^{5}$, o curso de Cirurgia na Bahia e o curso de Anatomia no Rio de Janeiro, futuros cursos de medicina (FÁVERO, 1977).

Além de criar o Jardim Botânico e a Biblioteca Nacional, para que a corte portuguesa desfrutasse de algumas das instituições acadêmico-científicas deixadas no além-mar, o Príncipe Regente D. João cria, em 04 de dezembro de 1810, a Academia Real Militar, a partir das instalações da Real Academia de Artilharia, Fortificação e Desenho. No oitocentos, esta Academia sofreria alterações desde sua denominação, organização e estrutura de funcionamento. Para abrigá-la, foi construído, no centro do Rio de Janeiro, no Largo de São Francisco, o primeiro prédio dedicado ao ensino superior de engenharia no Brasil, que, desde 1812 até 1966, permaneceu como centro do ensino de engenharia, permitindo também, a partir de 1858, a formação de engenheiros militares e civis (PARDAL, 1985).

No entanto, com o Decreto $\mathrm{n}^{\circ} 5.529$, de 17 de janeiro de 1874, o exército deixa a formação de engenheiros para instituições civis e, então, nasce a primeira escola de engenharia: a Escola Politécnica do Largo de São Francisco. Em suas salas, ocorreram, no Brasil, as primeiras demonstrações públicas de ciência no país: de transmissão telegráfica (1851), de iluminação a gás de mamona - (1851), de iluminação elétrica (1857), e de chapas de radiografia (1896) no país (PARDAL, 1985). É interessante registrar que a Academia Real é a raiz do atual Instituto Militar de Engenharia ${ }^{6}$ $I M E$, o qual tem por missão a formação de engenheiros em diversas habilitações.

Provavelmente, baseado na experiência anterior do final do século XVIII, o Observatório Nacional é criado, no Morro do Castelo, em 1827, por Decreto de D. Pedro I, cuja ocupação principal era a instrução de alunos das escolas militares de terra e mar. Em 1871, o observatório é retirado da administração militar e passa a ser dedicado a funções de pesquisa de meteorologia, astronomia, geofísica e medição do tempo e da hora ${ }^{7}$.

Ao longo do século XIX, outras tantas experiências de instituições científicas foram de-

\footnotetext{
${ }^{5}$ Atual Escola Naval, organização militar da Marinha do Brasil, que outorga o título de Bacharel em Ciências Navais.

${ }^{6} \mathrm{O}$ IME é uma organização militar do Exército Brasileiro. Disponível em: <http://www.ime.ib.br>. Acesso em: 20 jul. 2007.

${ }^{7}$ Ver sítio do Observatório Nacional , onde há um histórico acerca do tema. Disponível em: <http://www.on.br>. Acesso em: 20 jul. 2007.
} 
senvolvidas, bem como criados diversos estabelecimentos de ensino para a formação profissional em nível superior, como, por exemplo, as escolas de medicina, os cursos jurídicos, além de cursos "técnicos superiores" para, inicialmente, atender às necessidades da corte portuguesa e, posteriormente, a uma consolidação do Brasil-Império. Porém todas estas experiências se constituíram em iniciativas isoladas e atreladas a determinados contextos específicos, como as escolas de engenharia: Escola de Minas e Metalurgia de Ouro Preto (1876), Escola Politécnica da Bahia (1887), Escola de Engenharia Mackenzie (1891), Escola Politécnica de São Paulo (1893), Escola de Engenharia de Pernambuco (1896) e a Escola de Engenharia de Porto Alegre (1896), sem, ainda, dispor de um sistema universitário (SCHWARTZMAN, 1979).

Cabe ressaltar, no entanto, que, na Constituição Imperial de 1824, no art. 179, inciso XXXIII (BRASIL, 1824), já se previa o estabelecimento de "Collegios, e Universidades, onde serão ensinados os elementos das Sciencias, Bellas Letras, e Artes", pretensão essa, relativa às universidades, que só logrará êxito formal no século XX. Neste sentido, com a reunião das escolas Politécnica, de Medicina e de Direito, em 1920, constituiu-se a primeira universidade do governo federal no Brasil, denominada de Universidade do Rio de Janeiro, atual Universidade Federal do Rio de Janeiro - UFRJ. Esse princípio de criação de universidades floresceu em outros diferentes estados brasileiros. Não obstante, por intermédio da perspectiva política de um regime liberal-democrático, em 1934, com um modelo diferenciado, é criada a Universidade de São Paulo, pelo governo paulista e, em 1935, é criada, também, a Universidade do Distrito Federal ${ }^{8}$, pelo governo distrital, que propugnava, como missão de sua Escola de Ciências, a formação de pesquisadores, reunindo professores pesquisadores brasileiros e estrangeiros (SCHWARTZMAN, 1979).

\section{A pós-graduação no Brasil}

Embora pudéssemos contar, por exemplo, com a instituição do Grau de Doutor em Ciências Matemáticas desde 1842 na Escola Militar?, apenas a partir de 1931 é que, no país, temos a possibilidade de implantação de cursos de pós-graduação. Por exemplo, em Sucupira (1977) o autor declara que:

O doutoramento obtido mediante simples defesa de tese sempre existiu no ensino superior brasileiro. Mas a idéia de cursos de doutorado surge, pela primeira vez, com a Reforma Francisco Campos, em 1931. O Estatuto das Universidades Brasileiras (Decreto n ${ }^{\circ} 19.851$, de 11 abril de 1931) previa o doutoramento de tipo europeu, com defesa de tese," atendidas outras exigências regulamentares dos respectivos institutos". Por sua vez, o Decreto $\mathrm{n}^{\circ} 19.852$, também de 11 de abril de 1931, que dispunha sobre a organização da Universidade do Rio de Janeiro, criava cursos regulares de doutorado no campo do direito e das ciências exatas e naturais. Tais cursos constituíam, de fato, uma pósgraduação, que hoje denominamos stricto sensu. ${ }^{10}$

\footnotetext{
${ }^{8}$ Esta universidade foi extinta pelo Decreto-Lei n 1063, de 20 de janeiro de 1939 e seus cursos foram absorvidos pela Universidade do Brasil, antiga Universidade do Rio de Janeiro.

${ }^{9}$ Ver Pardal (1986), que apresenta um histórico dessa titulação na Escola Politécnica da atual UFRJ.

${ }^{10}$ Vale registrar o disposto no art. 90 do Decreto n 19.851, de 11 de abril de 1931 (BRASIL, 1931): Além dos diplomas e certificados referidos nos artigos e parágrafos anteriores, os institutos universitários de que trata o art. $5^{\circ}$, item I, expedirão diplomas de doutor quando, após a conclusão dos cursos normais, técnicos ou científicos, e atendidas outras exigências regulamentares dos respectivos Institutos, o candidato defender uma tese de sua autoria. $\S 1^{\circ}$. A tese, de que trata este artigo, para que seja aceita pelo respectivo instituto, deverá constituir publicação de real valor sobre assunto de natureza técnica ou puramente científica. $\S 2^{\circ}$. A defesa de tese será feita perante uma comissão examinadora, cujos membros deverão possuir conhecimentos especializados da matéria.
} 
Estatuto das Universidades Brasileiras de 1931 (BRASIL, 1931, grifo nosso), consagrava também os critérios gerais de organização das universidades, apresentando uma preocupação com a investigação, dispondo:

art. $1^{\circ}$ - $\bigcirc$ ensino universitário tem como finalidade: elevar o nível da cultura geral, estimular a investigação científica em quaisquer domínios dos conhecimentos humanos; habilitar ao exercício de atividades que requerem preparo técnico e científico superior; concorrer, enfim, pela educação do indivíduo e da coletividade, pela harmonia de objetivos entre professores e estudantes e pelo aproveitamento de todas as atividades universitárias, para a grandeza na Nação e para o aperfeiçoamento da Humanidade.

Cabe salientar, ainda, que o Estatuto da Universidade do Brasil (antiga Universidade do Rio de Janeiro), aprovado pelo Decreto $n^{\circ} 21.321$, de 18 de junho de 1946 (BRASIL, [19-?], grifo nosso) e tomado como referência pelas outras instituições de ensino superior no país, evidenciava em seus artigos os princípios da pós-graduação:

art. 71. Os cursos universitários serão os seguintes: a) cursos de formação; b) cursos de aperfeiçoamento; c) cursos de especialização; d) cursos de extensão; e) cursos de pós-graduação; f) cursos de doutorado;

art. 76 Os cursos de pós-graduação, destinados aos diplomados, terão por fim especial a formação sistemática de especialização profissional, de acordo com o que for estabelecido pelo regimento; e

art. 77 Os cursos de doutorado serão criados pelas escolas e faculdades e definidos nos respectivos regimentos, segundo as conveniências específicas.

Esses princípios estatutários avançaram na criação de universidades, mas não prosperaram em uma efetiva implantação da pós-graduação brasileira. Apenas, a partir dos anos 60, é que várias instituições de ensino superior dão início a um movimento nacional de implantação de cursos de mestrado em diversas áreas do saber.

No entanto, mesmo antes dos anos 50, algumas instituições de ensino superior e instituições e/ou associações científicas já desempenhavam um papel importante para o desenvolvimento das ciências e da tecnologia no país, como: Instituto de Manguinhos (atual Fundação Oswaldo Cruz), Observatório Nacional, Instituto Butantã, Academia Brasileira de Ciências, Clube de Engenharia ${ }^{11}$, Centro Brasileiro de Pesquisas em Física (CBPF), Instituto Nacional de Tecnologia (INT), Instituto de Pesquisa e Tecnologia (IPT), dentre outros. Todavia, foi por meio da criação das agências de fomento como Conselho Nacional de Desenvolvimento Científico e Tecnológico-CNPq, Coordenação de Aperfeiçoamento de Pessoal de Nível Superior-CAPES, e a Financiadora de Estudos e Projetos - FINEP, instituída já nos anos 60 que se tornou possível concretizar a pós-graduação nacional, em particular na área de engenharia.

Conselho Nacional de Pesquisas, atual CNPq, foi constituído pela Lei $n^{\circ}$, 1.310, de 1951 (BRASIL, [200-], grifo nosso) cuja finalidade está prevista no art. $1^{\circ}$ e cujas competências estão contidas no art. $3^{\circ}$ :

\footnotetext{
${ }^{11}$ Em Honorato e outros (1996), há registro de várias obras de engenharia com pioneirismo tecnológico envolvendo a engenharia nacional.
} 
art. $1^{\circ}$ : É criado o Conselho Nacional de Pesquisas, que terá por finalidade promover e estimular o desenvolvimento da investigação científica e tecnológica em qualquer domínio do conhecimento;

art.3: a) promover investigações cientificas e tecnológicas por iniciativa própria, ou em colaboração com outras instituições do país ou do exterior; b) estimular a realização de pesquisas cientificas ou tecnológicas em outras instituições oficiais ou particulares, concedendo-Ihes os recursos necessários, sob a forma de auxílios especiais, para aquisição de material, contrato e remuneração de pessoal e para quaisquer outras providências condizentes com os objetivos visados; c) auxiliar a formação e o aperfeiçoamento de pesquisadores e técnicos, organizando ou cooperando na organização de cursos especializados, sob a orientação de professores nacionais ou estrangeiros, concedendo bolsas de estudo ou de pesquisa e promovendo estágios em instituições técnico-cientificas e em estabelecimentos industriais no país ou no exterior; d) cooperar com as universidades e os institutos de ensino superior no desenvolvimento da pesquisa científica e na formação de pesquisadores; e) entrar em entendimento com as instituições, que desenvolvem pesquisas, a fim de articular-Ihes as atividades para melhor aproveitamento de esforços e recursos; f) manter-se em relação com instituições nacionais e estrangeiras para intercâmbio de documentação técnico-científica e participação nas reuniões e congressos, promovidos no país e no exterior, para estudo de temas de interesse co- mum; g) emitir pareceres e prestar informações sobre assuntos pertinentes às suas atividades e que sejam solicitados por órgão oficial; h) sugerir aos poderes competentes quaisquer providências, que considere necessárias à realização de seus objetivos.

A partir de sua criação e de acordo com a legislação supra-citada, esta agência foi, ao longo de sua evolução se consolidando como organismo de fomento, chegando aos dias atuais como Conselho Nacional de Desenvolvimento Científico e Tecnológico - $\mathrm{CNPq}^{12}$.

Os investimentos realizados pelo $\mathrm{CNPq}$ foram sendo direcionados ao financiamento de projetos de pesquisa para apoio à $\mathrm{Ci}$ ência e Tecnologia (C\&T), o que gerou uma participação ativa na formação de pesquisadores e grupos de investigação em várias áreas de conhecimento. Atualmente, esta agência do Ministério da Ciência e Tecnologia (MCT) tem como princípio "promover e fomentar o desenvolvimento científico e tecnológico do país e contribuir na formulação das políticas nacionais de C\&T".

A Coordenação de Aperfeiçoamento de Pessoal do Ensino Superior - CAPES, foi criada a partir do Decreto $n^{\circ} 29.741$, de 11 de julho de 1951 (BRASIL, 1951, grifo nosso), que instituía uma Comissão para promover a "Campanha Nacional de Aperfeiçoamento de Pessoal de Nível Superior", cujos objetivos estão dispostos no:

art. $2^{\circ}$ - A Campanha terá por objetivos: a) assegurar a existência de pessoal especializado em quantidade e qualidade suficientes para atender às necessidades dos empreendimentos públicos

${ }^{12}$ Ver sítio do CNPq. Disponível em: <http://www.cnpq.br >. Acesso em: 20 jul. 2007. 
e privados que visam ao desenvolvimento econômico e social do país; b) oferecer aos indivíduos mais capazes, sem recursos próprios, acesso a todas as oportunidades de aperfeiçoamentos.

Já o seu art. $3^{\circ} \mathrm{faz}$ referência às estratégias de consecução dos objetivos pela Comissão:

a) promover o estudo das necessidades do país em matéria de pessoal especializado, particularmente nos setores onde se verifica escassez de pessoal em número e qualidade; b) mobilizar, em cooperação com as instituições públicas e privadas, competentes, os recursos existentes no país para oferecer oportunidades de treinamento, de modo a suprir as deficiências identificadas nas diferentes profissões e grupos profissionais; c) promover em coordenação com os órgãos existentes o aproveitamento das oportunidades de aperfeiçoamento oferecidas pelos programas de assistência técnica da Organização das Nações Unidas, de seus organismos especializados e resultantes de acordos bilaterais firmados pelo Governo brasileiro; d) promover, direta ou indiretamente, a realização dos programas que se mostrarem indispensáveis para satisfazer às necessidades de treinamento que não puderem ser atendidas na forma das alíneas precedentes; e) coordenar e auxiliar os programas correlatos levados a efeito por órgãos da administração federal, governos locais e entidades privadas; f) promover a instalação e expansão de centros de aperfeiçoamentos e estudos post-graduados.
A CAPES ${ }^{13}$, hoje, é uma Fundação do Ministério da Educação (MEC), que tem buscado cumprir o seu papel na implantação e consolidação de mestrados e doutorados em todas as unidades federativas do Brasil, investindo nos cursos e na formação de pessoal qualificado e subsidiando o MEC na formulação de políiticas públicas para a pós-graduação nacional. Suas atividades básicas compreendem quatro linhas de ação: avaliação da pós-graduação stricto sensu (mestrado e doutorado), acesso à divulgação da produção cientííca, investimentos na formação de recursos humanos de alto nível no país e no exterior e a promoção da cooperação científica internacional.

Outra agência importante para apoio à construção do sistema de pós-graduação é a Financiadora de Estudos e Projetos - FINEP ${ }^{14}$. Empresa pública, hoje vinculada ao MCT, cuja data de criação é 24 de julho de 1967, através do Decreto $n^{\circ}$ 61.056, de 1967 (BRASIL, 1967, grifo nosso), com a função de gerenciar o Fundo de Financiamento de Estudos de Projetos e Programas, estabelecendo que:

art. $2^{\circ}$ - A FINEP tem por objetivo o financiamento da elaboração de estudos de projetos e programas de desenvolvimento econômico, aplicando prioritariamente os recursos de que dispunha nos estudos que visem à implementação das metas setoriais estabelecidas no plano de ação do Governo, elaborado sob a responsabilidade do Ministério do Planejamento e Coordenação Geral. Parágrafo único - A FINEP atuará também no sentido de contribuir para o aperfeiçoamento da tecnologia nacional, principalmente no que concerne à engenharia de projetos e assistência técnica.'

${ }^{13}$ Ver sítio da CAPES. Disponível em: <http://www.capes.gov.br>. Acesso em: 20 jul. 2007.

${ }^{14}$ Ver sítio da FINEP. Disponível em: <http://www.finep.gov.br>. Acesso em: 20 jul. 2007. 
Essa agência substituiu e ampliou a função até então exercida pelo Banco Nacional de Desenvolvimento Econômico - BNDE, ${ }^{15}$ e o seu Fundo de Desenvolvimento TécnicoCientífico - FUNTEC, constituído em 1964, que nos seus primeiros 10 anos forneceu 100 milhões de dólares para pesquisa e o treinamento em pós-graduação em engenharia, ciências exatas e outros campos (SCHWARTZMAN, 1979). A partir da década de 70, a FINEP promoveu intensa mobilização da comunidade científica, subsidiando diversos projetos, entre eles, a implantação de novos grupos de pesquisa, a criação de programas temáticos, a expansão da infra-estrutura de C\&T e a consolidação institucional da pesquisa e da pós-graduação no país. Estimulou, também, a articulação entre universidades, centros de pesquisa, empreendimentos privados, empresas de consultoria e contratantes de serviços, produtos e processos.

Nos dias de hoje, a FINEP ampliou suas atividades, tendo por missão promover e financiar a inovação e a pesquisa científica e tecnológica em empresas, universidades, institutos tecnológicos, centros de pesquisa e outras instituições públicas ou privadas, mobilizando recursos financeiros e integrando instrumentos para o desenvolvimento econômico e social do país.

Concomitante com a atuação das agências nacionais de fomento, surgiu a necessidade de regulamentação dos programas de pós-graduação no Brasil. É nesse contexto que o MEC encaminhou um aviso ministerial para apreciação do Conselho Federal de Educação - CFE ${ }^{16}$ (órgão do Ministério da Educação), solicitando o pronunciamento deste acerca da matéria (Sucupira, 1977). Daí o parecer resultante dessa demanda, que recebeu $0 \mathrm{n}^{\circ}$ 977/65, da Comissão de Educação Superior, do então CFE, e foi emitido pelo Conselheiro Newton Sucupira ${ }^{17}$, cujo estudo enfocou a pósgraduação, conceituando os tipos de cursos que deveriam ser ministrados no país. Tornouse, assim, um documento doutrinário para o setor, uma referência basilar da estrutura e funcionamento dos cursos brasileiros, permitindo a organização do processo de autorização e credenciamento dos mesmos com um padrão mínimo de qualidade.

A estrutura do Sistema Nacional de PósGraduação orientada pelo parecer CFE $n^{\circ}$ 977/65 (CONSELHO FEDERAL DE EDUCAÇÃO, 1965), deveria dar as seguintes características para os cursos na modalidade stricto sensu: são de natureza acadêmica e de pesquisas e, mesmo atuando em setores profissionais têm objetivo essencialmente científico. Já os cursos lato sensu privilegiam um sentido prático-profissional. Estes últimos cursos deveriam conferir certificado, enquanto os cursos stricto sensu, diploma. A pós-graduação stricto sensu compreende, por conseguinte, programas de mestrado e doutorado, enquanto na lato sensu são oferecidos programas na forma de cursos de especialização. $\bigcirc$ resultado dessa estrutura acadêmica permitiu, ao longo do tempo, a ampliação significativa da comunidade científico-nacional e um expressivo crescimento de sua produção intelectual.

\footnotetext{
${ }^{15}$ Atual Banco Nacional de Desenvolvimento Econômico e Social - BNDES. Disponível em: < (http://www.bndes.gov.br>. Acesso em: 20 jul. 2007.

${ }^{16}$ Através da Lei n 9.131, de 24 de novembro de 1995 (BRASIL, 1995), o CFE foi extinto e o Conselho Nacional de Educação - CNE, foi criado.

${ }^{17}$ Em Sucupira (1977), o próprio Conselheiro faz um registro histórico sobre o parecer e seus antecedentes como: a Lei de Diretrizes e Bases da Educação de 1961 e a lei de criação da Universidade de Brasília, dentre outros marcos interessantes da educação brasileira.
} 
A pós-graduação, hoje, exerce ainda um papel dinamizador na ampliação e renovação de campos específicos do saber.

As agências CNPq, CAPES e FINEP, aliadas à regulamentação e organização orientadas pelo Parecer no 977/65 do CFE, o qual teve importância fundamental na definição conceitual e na moldura legal da pós-graduação, efetivamente apoiaram a criação de cursos de pós-graduação stricto sensu. Além desses marcos da pós-graduação no Brasil, o sistema consolida-se, de fato, a partir da Reforma Universitária, introduzida pela Lei n ${ }^{\circ} 5.540$, de 28 de novembro de 1968. No intuito de "modernizar a universidade para um projeto econômico em desenvolvimento", a pós-graduação ganha fôlego e passa a ter o reconhecimento necessário ao seu desafio de ampliação ${ }^{18}$ (CURY, 2005). Estrategicamente, os Planos Nacionais de Pós-Graduação - PNPG (2005), constituíram-se, também, a partir de 1975, em outro elemento essencial na construção e desenvolvimento do sistema de pós-graduação.

\section{A pós-graduação em engenharia}

$\bigcirc$ primeiro curso de pós-graduação em engenharia foi criado em 1961 no Instituto Tecnológico de Aeronáutica - ITA ${ }^{19}$, o qual, desde o princípio de criação, contava com um corpo docente de elevado padrão, procurando reunir professores estrangeiros e brasileiros de alto nível. Estes orientavam professores mais jovens, aos quais eram oferecidas amplas oportunidades de prosseguir estudos avançados no país e no exterior. Desde a sua criação, houve, no ITA, o que se chama de atividade de pós-graduação no sentido lato (seminários, cursos especiais avançados, cursos de atualização, entre outros), por meio da qual se buscava melhor qualificação do docente iniciante, preparando-o, não somente para as tarefas de ensino, mas também para o prosseguimento de estudos no exterior. Em 1961, essas atividades foram organizadas formalmente em uma estrutura de disciplinas de pós-graduação e tese, iniciando-se um programa de formação de Mestres nos ramos da Engenharia Aeronáutica, Eletrônica e Mecânica, em Física e em Matemática.

Primeiro título de Mestre do Instituto Tecnológico de Aeronáutica foi conferido em 1963 e o primeiro título de Doutor, em 1970, marcando o pioneirismo do ITA em termos nacionais. Em 19 de Julho de 1970, o CNPq incluía o ITA entre os centros de excelência em Pós-Graduação em Engenharia e, a 4 de Junho de 1975, o Conselho Federal de Educação - CFE - credenciava os Cursos de Pós-Graduação do ITA, em nível de Doutorado. A partir de 1995, os cursos do ITA são credenciados pela CAPES, em vista dos conceitos recebidos.

Acompanhando o momento histórico propício e mais tarde alavancada por um volume significativo de recursos do FUNTEC/BNDE, em 1963, foi criado, pioneiramente, o curso de pósgraduação em engenharia química, por iniciativa do Prof. Alberto Coimbra, que, a despeito dos obstáculos e resistências encontrados dentro da própria UFRJ20, à época denominada Universidade do Brasil, implementou o programa que seria o embrião da futura coordenação dos programas de pós-graduação em engenha-

\footnotetext{
${ }^{18}$ Em Cury (2005), há uma contextualização acerca desse momento histórico.

19 O ITA é uma organização militar da Força Aérea Brasileira dedicada à formação de engenheiros. Disponível em: <http:// www.ita.br>. Acesso em: 20 jul. 2007.

${ }^{20}$ Em Sucupira (1977), há uma menção sobre a criação do Instituto de Química da UFRJ, que já possuía em seu regimento de 1962 as definições para uma pós-graduação.
} 
ria, isto é, a $\mathrm{COPPE}^{21}$. A partir dessa iniciativa, outros cursos de engenharia vão sendo criados na COPPE com apoio do FUNTEC, que foi fundamental para a consolidação da atual vitoriosa experiência de um dos maiores centros de formação de pesquisadores e investigação em engenharia do país. Registre-se que, além dos recursos recebidos, também outras atividades impulsionaram o empreendimento desta instituição, como o investimento no corpo docente que parece ter sido prioritário, uma vez que, desde o recrutamento, já se optou pelos melhores estudantes de engenharia que concluíam seus mestrados e que, em seguida, eram estimulados a serem intitulados no exterior, nas melhores escolas da Europa e Estados Unidos em programas de doutoramento (COSTA, 2005). Some-se a isso, o fato de que o regime de trabalho adotado era o de tempo integral com remuneração condizente, permitindo dedicação exclusiva a um projeto em construção, onde tal filosofia demonstrou ser vanguarda, nesse caso específico, já que a famosa "dedicação exclusiva (DE)" só seria adotada como política de pessoal pelo MEC, a partir dos anos 80. Nesse contexto, o primeiro título de mestrado em engenharia química foi outorgado em 29 de janeiro de 1964, e em 1965 dezesseis outros mestres nessa área obtiveram seu diploma: o primeiro título de doutorado em engenharia civil seria outorgado em 1970.

A Pontifícia Universidade Católica do Rio de Janeiro - PUC-Rio ${ }^{22}$ também inaugurou seu mestrado em engenharia em 1963, na área de Engenharia Elétrica. Em 1964, iniciou-se a pós-graduação em engenharia mecânica (mestrado) e, em 1965, a pós-graduação em Engenharia Civil (mestrado). Neste mesmo ano, foi apresentada a primeira dissertação de mestrado em Engenharia Mecânica ${ }^{23}$.

A partir daí, vários programas stricto sensu na área de engenharia foram surgindo por meio da articulação de auxílios e bolsas do CNPq e da CAPES, bem como do apoio da FINEP para a infra-estrutura e instalação de laboratórios, em especial ao preconizado no Decreto n ${ }^{\circ}$ 67.348, de 06 de outubro de 1970 (BRASIL, [200-]), que instituía o Programa Intensivo de pós-graduação, nas áreas ligadas ao Desenvolvimento Tecnológico do País.

Atentos a essas preocupações de desenvolvimento de ciência e tecnologia, os Estados passaram a exercer uma ação complementar por meio de suas próprias agências de fomento como a FAPESP24, FAPER ${ }^{25}$, FAPEMIG ${ }^{26}$, entre outras, que atuam em "sistema de colaboração" com as agências nacionais, preenchendo as lacunas ocasionadas pelo montante de recursos necessários ao atendimento dos projetos e da montagem de seus respectivos laboratórios. Além disso, essas agências regionais têm iniciativas próprias, realizando editais criativos que valorizam e estimulam a investigação local.

Atualmente, segundo a CAPES, há 2211 cursos de mestrado e 1246 de doutorado no país. Quanto às engenharias, as áreas de pós-graduação subdividem-se em quatro grandes grupos:

\footnotetext{
${ }^{21}$ Ver sítio da COPPE. Disponível em: <http://www.coppe.ufri.br>. Acesso em: 20 jul. 2007.

22 Ver sítio da PUC-Rio. Disponível em: < (http://www.puc-rio.br>. Acesso em: 23 jul. 2007.

${ }^{23}$ Tanto na UFRJ quanto na PUC-Rio, os programas de pós-graduação em engenharia tiveram um grande apoio do FUNTEC e do Fundo Nacional de Desenvolvimento Científico e Tecnológico - FNDCT, administrado à época pela FINEP.

${ }^{24}$ Ver sítio da Fundação de Amparo à Pesquisa do Estado de São Paulo - FAPESP. Disponível em: < (http://www.fapesp.br>. Acesso em: 23 jul. 2007.

${ }^{25}$ Ver sítio da Fundação Carlos Chagas Filho de Amparo à Pesquisa do Estado do Rio de Janeiro - FAPERJ. Disponível em: <http://www.faperi.br>. Acesso em: 23 jul. 2007.

${ }^{26}$ Ver sítio da Fundação de Amparo à Pesquisa do Estado de Minas Gerais - FAPEMIG. Disponível em: <http://www.fapemig.br>. Acesso em: 23 jul. 2007.
} 
Engenharia I, englobando a Engenharia Civil e afins; Engenharia II, que engloba a Engenharia de Minas e suas afins; Engenharia III, que englo- ba a Engenharia Mecânica e suas afins e, por fim, a Engenharia IV, englobando a Engenharia Elétrica e suas afins, conforme tabela a seguir:

Tabela 1 - Mestrados/Doutorados Reconhecidos

\begin{tabular}{|c|c|c|c|c|c|c|c|c|c|}
\hline \multicolumn{10}{|c|}{ GRANDE ÁREA: ENGENHARIAS } \\
\hline \multirow[t]{2}{*}{ ÁREA (ÁREA DE AVALIAÇÃO) } & \multicolumn{5}{|c|}{$\begin{array}{l}\text { Programas e Cursos } \\
\text { de pós-graduação }\end{array}$} & \multicolumn{4}{|c|}{$\begin{array}{l}\text { Totais de Cursos } \\
\text { de pós-graduação }\end{array}$} \\
\hline & Total & $M$ & D & $\mathrm{F}$ & $M / D$ & Total & $M$ & $\mathrm{D}$ & $\mathrm{F}$ \\
\hline $\begin{array}{l}\text { ENGENHARIA AEROESPACIAL } \\
\text { (ENGENHARIAS III) }\end{array}$ & 3 & 0 & 0 & 1 & 2 & 5 & 2 & 2 & 1 \\
\hline $\begin{array}{l}\text { ENGENHARIA BIOMÉDICA } \\
\text { (ENGENHARIAS IV) }\end{array}$ & 6 & 2 & 0 & 1 & 3 & 9 & 5 & 3 & 1 \\
\hline $\begin{array}{l}\text { ENGENHARIA CIVIL } \\
\text { (ENGENHARIAS I) }\end{array}$ & 47 & 25 & 0 & 3 & 19 & 66 & 44 & 19 & 3 \\
\hline $\begin{array}{l}\text { ENGENHARIA DE MATERIAIS E METALÚRGICA } \\
\text { (ENGENHARIAS II) }\end{array}$ & 32 & 9 & 0 & 2 & 21 & 53 & 30 & 21 & 2 \\
\hline $\begin{array}{l}\text { ENGENHARIA DE MINAS } \\
\text { (ENGENHARIAS II) }\end{array}$ & 4 & 3 & 0 & 0 & 1 & 5 & 4 & 1 & 0 \\
\hline $\begin{array}{l}\text { ENGENHARIA DE PRODUÇÃO } \\
\text { (ENGENHARIAS III) }\end{array}$ & 34 & 16 & 1 & 6 & 11 & 45 & 27 & 12 & 6 \\
\hline $\begin{array}{l}\text { ENGENHARIA DE TRANSPORTES } \\
\text { (ENGENHARIAS I) }\end{array}$ & 9 & 4 & 0 & 1 & 4 & 13 & 8 & 4 & 1 \\
\hline $\begin{array}{l}\text { ENGENHARIA ELÉTRICA } \\
\text { (ENGENHARIAS IV) }\end{array}$ & 48 & 17 & 0 & 7 & 24 & 72 & 41 & 24 & 7 \\
\hline $\begin{array}{l}\text { ENGENHARIA MECÂNICA } \\
\text { (ENGENHARIAS III) }\end{array}$ & 42 & 13 & 1 & 6 & 22 & 64 & 35 & 23 & 6 \\
\hline $\begin{array}{l}\text { ENGENHARIA NAVAL E OCEÂNICA } \\
\text { (ENGENHARIAS III) }\end{array}$ & 3 & 1 & 0 & 0 & 2 & 5 & 3 & 2 & 0 \\
\hline $\begin{array}{l}\text { ENGENHARIA NUCLEAR } \\
\text { (ENGENHARIAS II) }\end{array}$ & 7 & 2 & 0 & 1 & 4 & 11 & 6 & 4 & 1 \\
\hline $\begin{array}{l}\text { ENGENHARIA QUÍMICA } \\
\text { (ENGENHARIAS II) }\end{array}$ & 31 & 15 & 2 & 1 & 13 & 44 & 28 & 15 & 1 \\
\hline $\begin{array}{l}\text { ENGENHARIA SANITÁRIA } \\
\text { (ENGENHARIAS I) }\end{array}$ & 19 & 8 & 0 & 5 & 6 & 25 & 14 & 6 & 5 \\
\hline Total de ENGENHARIAS & 285 & 115 & 4 & 34 & 132 & 417 & 247 & 136 & 3 \\
\hline
\end{tabular}

Fonte: CAPES (2007).

Legenda: Cursos: M - Mestrado Acadêmico, D - Doutorado, F - Mestrado Profissional

Programas: M/D - Mestrado Acadêmico / Doutorado, M/F - Mestrado Acadêmico / Mestrado Profissional, D/F - Doutorado / Mestrado Profissional, M/D/F - Mestrado Acadêmico / Doutorado / Mestrado Profissional 
Em que pese o já considerável número de cursos de pós-graduação em Engenharia em funcionamento (417), os dados da tabela anterior apresentam duas características que merecem reflexão. A primeira diz respeito às modalidades dos cursos que se concentram em áreas tradicionais como a elétrica, mecânica e metalúrgica. Estas três modalidades, indicadas em destaque na tabela, representam mais de $45 \%$ do total de cursos. $\bigcirc$ Brasil precisa formar quadros de engenheiros (em nível de pós-graduação) em áreas mais estratégicas e que podem contribuir para tornar o país mais competitivo como, por exemplo: na nanotecnologia, na química fina, em energias alternativas, dentre outras.

Outra característica que chama a atenção está relacionada ao número de cursos de Engenharia em relação às demais áreas do conhecimento, comparando ao número total de cursos de pósgraduação, por nível (mestrado e doutorado), recomendados pela CAPES, atualmente em funcionamento no Brasil. Fica evidenciado que o número de cursos de pós-graduação em engenharia representa em torno de $12 \%$ do total de cursos, ou seja, muito pouco num cenário mundial de competição tecnológica. Isso somado ao número de concluintes de cursos de graduação em Engenharia, em torno de 3,3\% (SESu/MEC) ${ }^{27}$, no mesmo ano, torna-se motivo de preocupação nacional. A preocupação se fundamenta na necessidade de formação de profissionais em quantidade e qualidade adequada para responder pelo desenvolvimento científico e tecnológico do país num momento histórico reconhecido como o século do conhecimento. A inovação científica e tecnológica carece de engenheiros titulados, em nível de mestrado e doutorado, capazes de promover a competitividade dos produtos e serviços do país. Portanto políticas de indução do crescimento e direcionamento dos cursos de pós-graduação em Engenharia se fazem necessárias com a urgência em que se deseja o crescimento nacional.

\section{Avaliação da pós-graduação em engenharia}

A CAPES é responsável pela avaliação e acompanhamento de cursos de mestrado, doutorado e mestrado profissional, no Brasil, cujo trabalho é reconhecido internacionalmente e respeitado atribuindo qualidade, aferida por meio de conceitos, aos cursos de pósgraduação no país. A avaliação da pósgraduação ${ }^{28}$ no país, data de 1976, e passou a ser fundamental para a concessão de auxílios tanto por parte das agências de fomento nacionais como dos organismos internacionais. Há o acompanhamento anual, que precede um trienal que é realizado para submeter os programas a uma criteriosa análise de desempenho, cujos resultados são enviados para homologação ao CNE e publicamente divulgados através de Portaria do Ministro da Educação.

Atualmente, os programas recebem conceitos na seguinte escala de 1 a 7 , sendo que: 1 e 2- o programa é reprovado; 3- significa um desempenho regular,

\footnotetext{
27 SESu/MEC: Secretaria de Educação Superior do Ministério da Educação, ano 2005.

${ }^{28}$ Em Sucupira (1977), há um depoimento sobre processo de avaliação iniciado pela CAPES.
} 
atendendo ao padrão mínimo exigido para autorização de curso de Mestrado; 4- é considerado bom desempenho; e mínimo para autorização de Doutorado 5- é a nota máxima para programas com apenas mestrado; e 6 e 7 - indicam desempenho equivalente a um alto padrão internacional. A aprovação de cursos novos é regida pelos mesmos critérios e parâmetros básicos utilizados na Avaliação Trienal da CAPES. Em 2004, foi criado um ambiente computacional denominado de Aplicativo para Propostas de Cursos Novos - APCN. Por meio desse sistema eletrônico, as instituições de ensino superior podem apresentar suas propostas de cursos novos de mestrado, doutorado e mestrado profissional ${ }^{29}$.

Um fator importante para o desempenho da pós-graduação encontra-se intimamente ligado a uma mobilização permanente da comunidade acadêmica nacional, bem como a um processo contínuo de integração com a comunidade científica internacional, orquestrado e apoiado pela CAPES e pelo CNPq. Ao lado disso, a pósgraduação conta com um planejamento de médio e de longo prazos que, desde cedo, incorporou um adequado sistema de avaliação institucional e financiamento do poder público (BRASIL, 2005).

A experiência bem-sucedida na expansão e na qualidade do sistema de pósgraduação pode ser creditada ao financiamento público e à institucionalização do processo contínuo de avaliação, exis- tente há 30 anos, organizado pela CAPES e realizado por pares da comunidade acadêmica dos cursos de pós-graduação. Embora, no início, a pós-graduação fosse orientada por um modelo flexível, ao longo de seu desenvolvimento foi perdendo essa característica no interior das instituições. $\bigcirc$ sistema de avaliação, interpretado de forma rígida, contribui para consolidar um modelo marcadamente seqüencial (mestrado/doutorado). (BRASIL, 2005).

Vale registrar que, na área das ciências básicas, há uma presença significativa de mestres na academia (universidades e instituições de pesquisa), que recebe cerca de metade dos egressos dos cursos de pós-graduação; mas expressivas frações, de quase 20\%, também desempenham outros tipos de trabalho, como na administração e serviços públicos, ou em empresas públicas e privadas. Outrossim, nas áreas tecnológicas, a proporção de mestres, atuando na academia, diminui bastante e, simetricamente, aumenta a dos que trabalham em empresas, alcançando cerca de 40\%. Já, nas áreas profissionais, a fração dos que atuam na academia equivale àquela observada nas áreas tecnológicas. A proporção dos mestres que têm sua principal atividade remunerada em escritórios e consultórios passa a ser expressiva, chegando a $20 \%$. A parcela dos que trabalham na administração e serviços públicos alcança 25\% (BRASIL, 2005).

\footnotetext{
${ }^{29}$ Como uma realidade presente nas Engenharias, o "mestrado profissional" é a designação que enfatiza estudos e técnicas diretamente voltadas ao desempenho de um alto nível de qualificação profissional. Esta ênfase é a única diferença em relação ao mestrado tradicional, ou seja, o acadêmico. Confere, pois, idênticos grau e prerrogativas, inclusive para o exercício da docência, e, como todo programa de pós-graduação stricto sensu, tem validade nacional do diploma condicionada ao reconhecimento prévio do curso (Parecer do CNE/Câmara de Educação Superior n 79/2002. Disponível em: < http://www.mec.gov.br/cne>. Acesso em: 23 jul. 2007.
} 
Dessa forma, percebemos que o sistema de avaliação da pós-graduação em Engenharia, implementado pela CAPES, foi fundamental não só para a constante busca por um padrão de qualidade cada vez maior em cursos stricto sensu, voltados à formação de docentes pesquisadores, mas também para a aplicação de pesquisas ao mercado de trabalho, o qual tem sido significativamente beneficiado com a ampliação da formação recebida por engenheiros em cursos de mestrado, doutorado e mestrado profissional. Cabe ponderar que, por meio desta última titulação, o Sistema Nacional de PósGraduação ampliou sua interface com os setores não-acadêmicos da sociedade brasileira, tendo em vista a formação de recursos humanos com o referido nível de titulação para o exercício de profissões outras, que não a de docente pesquisador.

Nesse sentido, pode-se dizer que a avaliação na pós-graduação de engenharia tem sido uma experiência positiva, que contribuiu para o rompimento com modelos estabelecidos e forçou, de maneira sistemática, uma revisão e, posteriormente, uma reescrita dos conceitos, princípios e finalidades que norteiam a formação do engenheiro no Brasil. Fragilidades são expostas sim, mas a transparência é a melhor forma de detectar estruturas e procedimentos necessários à realização de um trabalho diferenciado de padrão internacional.

Vale ressaltar que o foco na avaliação representa, também, uma nova abordagem para a educação em Engenharia no nível da graduação, que por meio do Sistema Nacional de Avaliação da Educação Superior, busca, no Brasil, consolidar-se como uma política de Estado, para além das descontinuidades governamentais. É, portan- to, uma forma de verificar os resultados como instrumento de atuação no desempenho e melhoria dos cursos de graduação em Engenharia.

\section{Considerações finais}

Embora os estudos científicos tenham chegado tardiamente ao Brasil, por meio de incipientes experiências realizadas pelos jesuítas, no século XX avançamos, rompendo com antigos estigmas e traçando novas identidades para as ciências e, em particular, para a Engenharia. A vinda da Família Real Portuguesa, há 200 anos, para a sua colônia mais próspera, pode ser afirmada como o marco inicial da formação superior de engenheiros que atuariam desde o aprimoramento de técnicas de construções militares até as edificações civis de infra-estrutura das províncias imperiais. A primeira escola oficial de engenharia é criada no Século XIX, a partir de então, várias outras escolas vão surgindo. Além disso, pode-se constatar que, desde 1842, na Escola Militar que formava engenheiros e, posteriormente, na Escola Politécnica do Rio de Janeiro, havia a outorga, através de provas e defesa de tese, de títulos do grau de doutor.

Apesar de experiências anteriores, as escolas de engenharia não se constituíram com a uniformidade que caracteriza um sistema universitário e, sim, em instituições isoladas que foram, ao longo das primeiras décadas do século XX, as incubadoras de onde saíram os quadros que conduziriam à implantação da primeira Universidade no Brasil. Por outro lado, o surgimento da primeira Universidade pode ser considerada a gênese da Pós-Graduação no Brasil, a qual já era vislumbrada no Estatuto das Universidades Brasileiras. Por con- 
seguinte, cabe ponderar que este fato marca as iniciativas pioneiras de tornar a pesquisa científica, também acadêmica.

A partir dos anos 50, com a criação do CNPq e CAPES, estas agências nacionais de fomento incentivaram a formação de pessoal titulados no exterior para atuar na pósgraduação brasileira. É nesse ambiente que as engenharias viabilizaram programas de pós-graduação, ressaltando-se o pioneirismo do ITA, da COPPE/UFRJ e da PUC-Rio. Para os programas de Mestrado e de Doutorado em engenharia, o apoio dessas agências, bem como o BNDE e, posteriormente, a FINEP, já nos anos 70, foi fundamental na criação e consolidação dos programas stricto sensu destas e demais instituições de ensino e pesquisa nacionais.

Na história da pós-graduação brasileira, constata-se, inicialmente, um movimento nacional para titulação dos docentes das universidades, seguida da regulamentação para criação e reconhecimento dos cursos de mestrado e doutorado, depois a preocupação com o desempenho do sistema de pós-graduação e, finalmente, volta-se para o desenvolvimento da pesquisa na univer- sidade. Hoje, o país sinaliza que a pesquisa científica e tecnológica e, em especial nas engenharias, é uma das prioridades para o desenvolvimento e soberania nacional. Entretanto deve-se ressaltar que sempre esteve presente a preocupação com os desequilíbrios regionais e com a flexibilização do modelo de pós-graduação nos planos nacionais, em particular, no PNPG 2005-2010 (BRASIL, 2005).

Por fim, falar da pós-graduação em engenharia no Brasil é uma determinação que exige fôlego. Além de ser uma das áreas pioneiras dos estudos superiores no Brasil, a engenharia é, também, o palco de ações que mudaram a ciência e técnica em nosso país. Assim sendo, qualquer relato que se disponha a essa tarefa é, por si só, simplista e arbitrário, já que terá que fazer escolhas e trará o viés do olhar das fontes que nos são mais caras em detrimento de outras.

Portanto, ao concluir esse relato, coubenos precipuamente levantar dados que deverão ser problematizados e investigados em seu todo e em partes para contribuir com a história da pós-graduação e, especialmente, a pós-graduação em engenharia no Brasil.

\section{Referências}

BRASIL. Decreto n. 19.851, de 11 de abril de 1931. Dispõe sobre o ensino superior no Brasil. Sicon, Brasília, DF, [20--?]. Disponível em: <http://www.senado.gov.br>. Acesso em: 23 jul. 2007.

BRASIL. Decreto n ${ }^{\circ}$ 1.063, de 20 de janeiro de 1939. Dispõe sobre a transferência de estabelecimentos de ensino da Universidade do Distrito Federal para a Universidade do Brasil. Diário Oficial da União, Rio de Janeiro, [1939?].

BRASIL. Decreto n. 21.321, de 18 de junho de 1946. Aprova o Estatuto da Universidade do Brasil. Diário Oficial da União, Rio de Janeiro, [1946?]. 
BRASIL. Lei n. 1.310, de 15 de janeiro de 1951. Cria o Conselho Nacional de Pesquisas e dá outras providências. Lei, Brasília, DF, [200-]. Disponível em: <http:// portal.cnpq.br/normas/lei_1310.htm - 42k >. Acesso em: 23 jul. 2007.

BRASIL. Decreto n. 29.741, de 11 de julho de 1951. Institui uma Comissão para promover a campanha nacional de aperfeiçoamento de pessoal de nível superior. Disponível em: <http://www6.senado.gov.br/legislacao/ListaPublicacoes.action? id=161737>. Acesso em: 23 jul. 2007.

BRASIL. Decreto n. 61.056, de 24 de julho de 1967. Constitui a Financiadora de Estudos de Projetos S.A. - FINEP e dá outras providências. Diário Oficial [da] República Federativa do Brasil, Brasília, DF, 25 jul. 1967.

BRASIL. Lei $n^{\circ}$. 5.540, de 28 de novembro de 1968. Fixa normas de organização e funcionamento do ensino superior e sua articulação com a escola média, e dá outras providências. Disponível em: <www.planalto.gov.br/CCIVIL/Leis/L5540.htm - 69k - >. Acesso em: 23 jul. 2007.

BRASIL. Decreto n. 67.348, de 6 de outubro de 1970. Institui o Programa Intensivo de pós-graduação, nas áreas ligadas ao Desenvolvimento Tecnológico do País, e dá outras providências. Prolei, Brasília, DF, [200-]. Disponível em: <http:// www.prolei.inep.gov.br>. Acesso em: 23 jul. 2007.

BRASIL. Lei n. 9.131, de 21 de novembro de 1995. Cria o Conselho Nacional de Educação. Brasília, DF, 1995. Disponível em: <http://www.planalto.gov.br/ccivil_03/leis/ L9649cons.htm>. Acesso em: 23 jul. 2007.

BRASIL. Lei $n^{\circ} .10 .861$, de 14 de abril de 2004. Institui o Sistema Nacional de Avaliação da Educação Superior (SINAES) e dá outras providências. Disponível em: <http:// portal.mec.gov.br/arquivos/pdf/leisinaes.pdf>. Acesso em: 23 jul. 2007.

BRASIL. Ministério da Educação. Plano Nacional de Pós-Graduação: PNPG 20052010. Brasília, DF, 2005.

CONSELHO FEDERAL DE EDUCAÇÃO (Brasil). Parecer no 977, de 3 de dezembro de 1965. Definição dos cursos de pós-graduação. Diário Oficial [da] República Federativa do Brasil, Brasília, DF, 20 jan. 1966.

COSTA, T. Engenharia da transparência: vida e obra de Lobo Carneiro. Rio de Janeiro: Andréa Jakobson Estúdio, 2005.

CUNHA, L. A. Qual universidade?. São Paulo: Cortez: Autores Associados, 1989. 
CURY, C. R. J. Quadragésimo ano do parecer CFE n 977/65. Revista Brasileira de Educação, Campinas, SP, n. 30, set./out./nov./dez. 2005.

FÁVERO, M. L. A. Universidade brasileira em busca de sua identidade. Petrópolis, RJ: Vozes, 1977.

HONORATO, C. T. et al. Clube de Engenharia nos momentos decisivos da vida do Brasil. Rio de Janeiro: Fundação Emílio Odebrecht: Clube de Engenharia, 1996.

PARDAL, P. Brasil, 1792: início do ensino de engenharia civil e da Escola de Engenharia da UFRJ. Rio de Janeiro: Fundação Emílio Odebrecht, 1985.

PARDAL, P. 140 anos de doutorado e 75 de livre docência no ensino de engenharia no Brasil. Rio de Janeiro: Escola de Engenharia, UFRJ, 1986.

PIMENTEL, L. S. Método lusitânico de desenhar as fortificações das praças regulares e irregulares. Lisboa: Direcção da Arma de Engenharia, 1680. Fac-simile, 1993.

SCHWARTZMAN, S. Formação da comunidade científica no Brasil. São Paulo: Companhia Editora Nacional: FINEP, 1979.

SUCUPIRA, N. Antecedentes e primórdios da pós-graduação. Fórum Educacional: revista da Fundação Getúlio Vargas, Rio de Janeiro, ano 4, n. 4, p. 3-18, out./dez. 1977.

Recebido em: 22/06/2007

Aceito para publicação em: 10/07/2007 